\title{
Poverty, physical stature, and cognitive skills: Mechanisms underlying children's school enrollment in Zambia.
}

\section{Citation}

McCoy, Dana Charles, Stephanie Simmons Zuilkowski, and Günther Fink. 2015. “Poverty, Physical Stature, and Cognitive Skills: Mechanisms Underlying Children's School Enrollment in Zambia." Developmental Psychology 51 (5): 600-614. doi:10.1037/a0038924.

\section{Published Version}

doi:10.1037/a0038924

\section{Permanent link}

http://nrs.harvard.edu/urn-3:HUL.InstRepos:23578225

\section{Terms of Use}

This article was downloaded from Harvard University's DASH repository, and is made available under the terms and conditions applicable to Open Access Policy Articles, as set forth at http:// nrs.harvard.edu/urn-3:HUL.InstRepos:dash.current.terms-of-use\#OAP

\section{Share Your Story}

The Harvard community has made this article openly available.

Please share how this access benefits you. Submit a story.

\section{Accessibility}


Poverty, Physical Stature, and Cognitive Skills: Mechanisms Underlying Children's School Enrollment in Zambia

\author{
Dana Charles McCoy ${ }^{1}$, Stephanie Simmons Zuilkowski ${ }^{2}$, Günther Fink ${ }^{1}$ \\ ${ }^{1}$ Harvard University \\ ${ }^{2}$ Florida State University
}

Address correspondence to:

Dana Charles McCoy

Harvard University

Center on the Developing Child

50 Church St, $4^{\text {th }}$ Floor

Cambridge, MA 02138

dana_mccoy@gse.harvard.edu

Acknowledgements: We are grateful for the financial support for the ZECDP project provided by UNICEF Zambia, Julie Henry and the Özyegin Family - AÇEV Global Early Childhood Research Fund through the Center on the Developing Child at Harvard University. We are also grateful for support from Grand Challenges Canada and the Saving Brains initiative. 
POVERTY, HEALTH, AND CHILD DEVELOPMENT

\begin{abstract}
Past research suggests robust positive associations between household socioeconomic status and children's early cognitive development in Western countries. Relatively little is known about these relations in low-income country settings characterized by economic adversity, high prevalence of malnutrition and infectious disease, and relatively lower school enrollment. The present study develops and empirically evaluates an adapted model of early childhood development using a sample of 2711 Zambian six-year-olds. Early learning in and out of the home was found to explain much of the relation between socioeconomic status and children's cognitive skills, including language, non-verbal reasoning, and executive function. Child heightfor-age (a proxy for overall nutritional status and health) was also predictive of children's cognitive skills and both early and on-time school enrollment. Implications for global child development, intervention, and future work are discussed.
\end{abstract}

Keywords: Child development, cognition, poverty, sub-Saharan Africa, Zambia 
POVERTY, HEALTH, AND CHILD DEVELOPMENT

\section{Poverty, Physical Stature, and Cognitive Skills: Mechanisms Underlying Children's School Enrollment in Zambia}

\section{Introduction}

Over the past several decades, a large body of research in the United States has analyzed the complex associations between family socioeconomic status (SES) and children's early cognitive development. This work has found consistent and negative relations between socioeconomic adversity (as measured by income poverty and/or low caregiver education) and children's cognitive skills, such as language, non-verbal reasoning, general intelligence, and executive function (Blair \& Raver, 2012; Hoff, 2003; Sameroff, Seifer, Barocas, Zax, \& Greenspan, 1987; Sirin, 2005). A wide range of conceptual frameworks of child development have highlighted caregiver inputs, early investments, and cognitively enriching environments as critical mediators in the relation between poverty and children's early outcomes (Duncan \& Brooks-Gunn, 2000; Gershoff, Aber, Raver, \& Lennon, 2007; Guo \& Harris, 2000; Lugo-Gil \& Tamis-LeMonda, 2008; McLoyd, 1998). These frameworks suggest that low-income children are less likely than their more economically advantaged peers to experience high-quality cognitive stimulation in their home and external early education environments, placing them at risk for reduced cognitive functioning prior to school entry and later in life.

Although the associations between SES, early stimulation, and children's development have been well explored in the United States using observational and experimental methods (Gershoff et al., 2007; Morris \& Gennetian, 2003), relatively little is known about these relations in low- and middle-income countries (LMICs) where an estimated 1.6 billion individuals live on less than US\$1.25 per day (Dhongde \& Minoiu, 2013). Conceptually, SES may not only be more salient in LMICs due to caregivers' particularly limited means to invest in early childhood 
POVERTY, HEALTH, AND CHILD DEVELOPMENT

stimulation within and outside the household, but also because socioeconomic adversity severely limits caregivers' ability to provide adequate nutrition and to protect their children from the generally high burden of infectious disease (Lozano et al., 2013; Wang et al., 2012).

The primary goal of the current study is to test an adapted model of SES and early childhood cognition in a sample of 2711 Zambian children. In particular, our model proposes that in many LMIC environments like Zambia, the explanatory power of a traditional parental investment model may be enhanced by considering additional variables of early childhood health and timing of primary school enrollment. We test the applicability of this expanded model by examining the direct and indirect relations between family SES (including household wealth and caregiver education), early investment in learning inside and outside of the home (including home-based learning materials and learning activities, and children's time in early childhood education programs), children's early health (as measured by height-for-age), children's cognitive skills (including language, executive function, and non-verbal reasoning), and both early and on-time school enrollment. This empirical evaluation serves as a first step towards determining the generalizability of this adapted model for use in a LMIC context, as well as towards identifying targets of intervention that maximize child outcomes in the context of particularly scarce resources.

\section{The Zambian Context}

A landlocked country in southern Africa, Zambia has a current population of just under 14 million (UNESCO, 2012). In 2013, Zambia ranked $141^{\text {st }}$ out of 187 countries on the Human Development Index (HDI) (United Nations Development Programme, 2014). Two of every three Zambian citizens live below the international poverty line of US\$1.25 per day, and 14 percent of adults and 28 percent of pregnant women are HIV-positive (Republic of Zambia, 
POVERTY, HEALTH, AND CHILD DEVELOPMENT

2012). The burdens that poverty and disease place on Zambian children are significant, with 45 percent of children under five estimated to be stunted (i.e., showing a height-for-age of less than two standard deviations below the international standard) and more than one in three households including an orphan or foster child (Central Statistical Office of Zambia and Macro International Inc., 2009).

Although Zambia faces challenges in the areas of health and socioeconomic advancement, in recent years great progress has been made in the area of primary education. More than 90 percent of children of primary school age are enrolled in Zambia, with attendance rates averaging around 80 percent (UNESCO, 2012). Literacy rates for youth ages 15 to 24 are over 80 percent for males and 67 percent for females, ranking Zambia $13^{\text {th }}$ out of 52 African nations in over-15 literacy (The African Economist, 2013; UNESCO, 2012). Despite advancement in primary education, Zambia has much room for improvement with respect to educational services provided. In 2008, Zambia spent just 1.8 percent of its GDP on education (compared to 5.5 percent in the United States; World Bank, 2013). In addition, there are currently no government sponsored pre-schools or early care centers in Zambia, and less than 20 percent of children entering primary school report any formal early childhood education experience (UNESCO, 2012). Disparities in access to early education are also seen based on urbanicity, with urban provinces such as Lukasa and Copperbelt showing significantly higher rates of preschool enrollment (51.4 percent) relative to rural areas like the Western Province (2.2 percent; UNICEF, 2013).

\section{Applying a Parental Investment Model to the Zambian Context}

Although high rates of poverty, health-related adversity, and early educational disparities in Zambia are well documented, the degree to which these risk factors relate to one another and 
POVERTY, HEALTH, AND CHILD DEVELOPMENT

to children's early outcomes remains unknown. In the present study, we aim to address this gap by testing a model of children's early development that explicitly considers the levels and types of adversity faced by representative Zambian families. To achieve this goal, we build upon a traditional model of parental investment developed based on decades of research from the United States and other Western contexts. In particular, this research describes how many of caregivers' opportunities to optimize their children's outcomes may be constrained by limited resources (e.g., time, money, human capital). Empirically, SES has been shown to be positively associated with both home-based caregiver investment in learning and with participation in high quality center-based early education programs in high-income countries, each of which has been shown to independently affect children's cognitive abilities (Burchinal, Campbell, Brayant, Wasik, \& Ramey, 1997; Davis-Kean, 2005; Guo \& Harris, 2000; Yeung, Linver, \& Brooks-Gunn, 2002). In turn, cognitive capacities such as executive function, pre-academic skills, and non-verbal reasoning have been labeled as essential components of children's school readiness, and found to be highly predictive of later reading and math achievement (Duncan et al., 2007).

As a result of this research, researchers, advocates, and governments around the world have increasingly focused on improving young children's cognitive development as a new priority of the international public health and education agendas. Home visiting programs and center-based preschools that promote early stimulation, for example, are often cited as critical mechanisms for reducing poverty-related disparities in low-resourced settings (Engle et al., 2011). Despite rapidly increasing public interest and investment in early childhood, there is very little evidence to confirm that models of SES, investment, and cognition are valid outside of Western contexts. Research is particularly scarce on the relative strength of the relationships between different dimensions of SES (e.g., household wealth vs. maternal education), different 
POVERTY, HEALTH, AND CHILD DEVELOPMENT

forms of stimulation (e.g., home-based practices vs. center-based care) and different dimensions of cognition (e.g., language, non-verbal reasoning, and higher-order executive functions). In the present study, we bring these processes together in a single, cohesive model in order to more fully understand 1) whether each of the relations observed in previous studies from the United States and other high-income contexts hold true for Zambian families, and 2) whether particular pathways between SES, stimulation, and cognition may be stronger than others, therefore implying greater opportunity for intervention.

\section{The Importance of Physical Stature and School Enrollment for Zambian Children}

Although the replication of an existing model in an understudied population is an important goal into and of itself, in the present study we attempt to strengthen this model by integrating two additional phenomena - children's physical stature and school enrollment - as variables of interest within this particular context. In recent years, physical stature, generally measured by height-for-age z-scores (HAZ) or stunting (HAZ $<-2)$, has been become the most widely used indicator of child development in the international literature on public health. As summarized by Grantham-McGregor et al. (2007), children's physical growth in the first years of life is not only a direct result of children's exposure to early life deprivation and adversity (including poverty, malnutrition, infection, and non-responsive parenting practices), but also a robust predictor of later life cognitive test performance in LMICs (Walker, Chang, Powell, Simonoff, \& Grantham-McGregor, 2007). Apart from serving as a proxy for childhood sickness and malnutrition, which have effects on children's cognitive skills through reducing their energy and ability to interact with their environment (Aburto, Ramirez-Zea, Neufeld, \& Flores-Ayala, 2009; Gardner, Grantham-McGregor, Himes, \& Chang, 1999), physical stature is likely to directly affect both the timing of children's transition to school and their subsequent trajectories 
POVERTY, HEALTH, AND CHILD DEVELOPMENT

within the schooling system (Adair et al., 2013; Dewey \& Begum, 2011).

Although access to primary schooling has become nearly universal in most LMICs as a result of the Millennium Development Goal and Education for All efforts (United Nations, 2013; 2014), lack of a clear governmental mandate on timing of enrollment has resulted in high variability in school entry age within many LMICs, including Zambia, with some children beginning primary school as early as five years old, and others waiting until age eight or later. This heterogeneity is a concern because timing of enrollment appears to matter for children's long-term outcomes. In Zambia, only 53 percent of children who start school continue to be enrolled at the end of primary school (UNESCO, 2012). Age is a critical factor in predicting dropout in sub-Saharan Africa (Buchmann, 2000; Fawcett, Hartwell, \& Israel, 2010; Lloyd \& Mensch, 2000; Piper, Jukes, \& Miguel, in prep; Schafer, 2006), with those children who enter school early or on time being less likely than those children who enter school late to drop out early (Grogan, 2009).

A small body of empirical evidence from LMICs suggests that both cognition and physical size are key indicators of "school readiness" for parents and teachers, with separate studies finding that more cognitively "able" and taller children tend to be enrolled in school earlier than their less "able" and shorter peers (Daniels \& Adair, 2004; Fentiman, Hall, \& Bundy, 2001; Glewwe \& Jacoby, 1995; Partnership for Child Development, 1999). At present, however, there is little research available from LMICs that explain the relative contributions of cognitive and physical markers of school readiness in predicting caregivers' choices to enroll their children in school either early or on time, as most of the existing literature in this area comes from the U.S. and focuses on the generally better academic performance (but not necessarily earlier enrollment) of older, taller, and more cognitively advanced children (Angrist \& Krueger, 1992; 
POVERTY, HEALTH, AND CHILD DEVELOPMENT

Gutman, Sameroff, \& Cole, 2003). Given the much larger variations in child height and timing of enrollment in LMICs, similar effects appear plausible, though the degree to which caregivers' perceptions of cognitive readiness are based on different representations of cognitive capacities (e.g., language-based versus non-verbal skills) remains unknown.

\section{The Present Study}

The present study seeks to validate an adapted version of a well-established Western model of early childhood SES, parental investment in stimulation, and cognition in Zambia by extending this framework to include 1) physical stature (height-for-age) as a mechanism in the pathway from SES to early cognition and 2) primary school enrollment as critical outcome of early childhood. This study uses structural equation modeling to simultaneously explore the direct and indirect relations between family SES, children's home- and center-based cognitive stimulation, height-for-age, cognitive skills, and the timing of children's school enrollment. (See Figure 1 for proposed conceptual model.) In particular, we test two separate models to understand the ways that these early characteristics predict 1) concurrent school enrollment (by age six) in the full sample, and 2) school enrollment one year later (by age seven) in a subset of children born in 2004. We hypothesize that although a traditional model of SES, investment, and cognition will hold true in Zambia (where early exposure to stimulation at home and in childcare settings will partially explain the relationships between SES and child cognitive skills), this model may not be fully adequate on its own for representing the full range of developmental experiences faced by Zambian children. For this reason, we also hypothesize that children's physical stature will serve as an important mechanism and proximal outcome of these pathways, with children from low SES, low-stimulation contexts showing reductions in cognitive skills via reduced height-for-age. Finally, we hypothesize that early SES and stimulation will be directly 
POVERTY, HEALTH, AND CHILD DEVELOPMENT

and indirectly related to children's early and on-time school enrollment through their relations with two potential markers of school readiness in Zambia: cognition and physical size.

\section{Method}

\section{Procedure}

To test the present model, we use data from the Zambia Early Childhood Development Project (ZECDP). The ZECDP was launched in 2009 with the objective of generating a comprehensive assessment of children's development as they transition to school using tools that are both internationally comparable and suitable for the sub-Saharan African context (Fink, Zuilkowski, \& Matafwali, 2011; Zuilkowski, Fink, Moucheraud, \& Matafwali, 2012). In collaboration with a local expert team, a child assessment battery was developed suitable for children of age six in Zambia. After extensive piloting in early 2010, two rounds of assessments were conducted in 73 randomly selected clusters across seven of Zambia's nine provinces as displayed in Figure 2. In 2010, the first cohort of children born in $2004(n=1766)$ was assessed in these clusters. In 2012, the second cohort of children born in $2006(n=945)$ was assessed in the same clusters. Each study cluster corresponds to an enumeration area used in the 2000 census, which typically corresponds to an entire village in rural areas and a block of 250 households in urban areas. For both cohorts, detailed measures of household wealth, home environment, and school enrollment were collected alongside a battery of child assessments during the year that children turned six years old ("wave one"). Data on children's school enrollment were also collected one year later (when children were turning seven, or "wave two") for the first cohort (those born in 2004) only. The multilingual local assessors received extensive training on assessment administration and research ethics. All data collection instruments and activities were approved by the institutional review boards of the Harvard School of Public Health, the 
POVERTY, HEALTH, AND CHILD DEVELOPMENT

University of Zambia, and Innovations for Poverty Action-Zambia. ${ }^{1}$

\section{Participants}

Participants in the present study included 2711 children from seven regions in Zambia. During the first wave of data collection, children were an average of 6.21 years old (range $=$ 5.58-7.00). Approximately 48 percent of participants were female, and about half came from urban areas. Full sample descriptive statistics can be found in Table 1.

\section{Measures}

Table 1 summarizes the main measures and constructs used in our analysis, and shows the mean, standard deviation, range, and number of valid observations for each. Measures included as primary variables of interest in the model were household SES, early investment in learning, physical stature, cognitive skills, and school enrollment, as well as a set of demographic controls. All measures with the exception of school enrollment at age seven were collected concurrently at wave one through a home visit interview. Interviews and assessments were generally conducted in the majority languages of the provinces in which we collected data Nyanja, Bemba, Tonga, and Lozi - though our multilingual assessors also carried versions of the assessments in other languages that may have been needed in their particular geographic area.

Socioeconomic status. Two measures of SES were explored: family wealth and years of caregiver education. To conceptualize family wealth, caregivers were asked to report on their household's asset holdings, including household ownership of a bike, cell phone, radio, TV, stove, access to electricity, access to running water, and solid floors in the house. Such an approach serves as a more pragmatic alternative to collecting income, occupation, or expenditure data in households where both money flow and household membership are volatile, seasonally

\footnotetext{
${ }^{1} \mathrm{~A}$ full description of the ZECDP is available at developingchild.harvard.edu/activities/global_initiative/zambian_project/.
} 
POVERTY, HEALTH, AND CHILD DEVELOPMENT

dependent, and/or difficult for participants to track. Empirically, this approach has also been found to be at least as reliable for predicting school enrollment in LMICs as traditional income measures (Filmer \& Pritchett, 2001). Primary caregivers (usually mothers) also reported on the number of years they had received formal education, which was included as a continuous representation of caregiver education.

Early investment in learning. Two measures of early investment in learning were used in the present study. First, home-based cognitive stimulation was represented by three items: whether there were any children's books in the home, whether there were any non-children's books in home, and whether an adult in the household spent time reading to the child in the past week. Although conceptually similar to the measures of family wealth and maternal education, the presence/absence of books in the home and caregivers' reading practices have been commonly used in previous work in LMICs to represent households" "cultures of learning" rather than their socioeconomic status (e.g., UNICEF's MICS-4 surveys, the Young Lives study). This assertion is supported in the present sample by small bivariate correlations across SES and early investment in learning items ( $r$ 's ranging from -.01 to .25 ), and exploratory factor analyses showing a multi-factor solution in which early investment in learning items load cleanly on a separate factor from household socioeconomic variables with no cross-loadings. (For full results, please contact first author.) As a second indicator of early investment in learning, years of early childhood education was treated as a continuous variable to represent formal experiences with early education out of the home.

Physical stature. Physical stature was measured with standard portable measurement kits during both survey rounds. Height, measured in centimeters, was converted into z-scores using the World Health Organization's Anthro Plus software (WHO, 2006) based on the revised 
POVERTY, HEALTH, AND CHILD DEVELOPMENT

international growth standard (de Onis et al., 2007). For cohort 1 (children born in 2004), the exact age of the child in months was used for the calculation of the age and gender-specific HAZ; for cohort 2 (children born in 2006), this variable was not collected due to administrative error. Instead, the age used to calculate HAZ was estimated based on the difference between July 1, 2006 (the mid-point of the children's year of birth) and the date of assessment.

Cognitive skills. Three domains of cognition were considered for the study: receptive language, non-verbal reasoning, and executive functioning. Details on all tasks used to capture cognitive skills can be found in Fink, Matafwali, Moucheraud, \& Zuilkowski, 2012. In summary, receptive language skills were measured by a locally developed assessment similar to the Peabody Picture Vocabulary Test (Dunn \& Dunn, 1997), which captured children's ability to pick one in a series of four pictures that best matched an assessor's oral description of an object, action, or concept (e.g., fruit, bathing, empty). The receptive language task included a total of 30 items scored as either pass (1) or fail (0), which were averaged to generate a scale of children's receptive language abilities.

Non-verbal reasoning skills were assessed using three standardized tests: a threedimensional block task similar to the NEPSY block test that included 12 items (Korkman, Kirk, \& Kemp, 1998), a paper-based pattern recognition task similar to the Kaufman pattern recognition task that included 18 items (Kaufman, 2004), and a newly developed task called the Tactile Patterns Reasoning measure that included 10 items and used beads, wooden blocks, and bottle caps to assess progressively more complex pattern recognition (Fink et al., 2012). All three tasks were designed to capture children's visiospatial ability to replicate two- and threedimensional patterns and figures using either paper-and-pencil or three-dimensional objects. Tasks were chosen based on their complementary ability to capture both two- and three- 


\section{POVERTY, HEALTH, AND CHILD DEVELOPMENT}

dimensional pattern reasoning (as initial piloting revealed inconsistent familiarity with twodimensional images within the sample) and to represent both well-established and newlydeveloped testing paradigms.

Executive function skills were measured through a locally-adapted pencil tap test (SmithDonald, Raver, \& Hayes, 2007) in which children were asked to tap a pencil once when an assessor tapped twice, and tap twice when an assessor tapped once. This task was designed to capture three dimensions of children's executive function: working memory (to retain the rules), attention (to what the assessor is doing), and inhibitory control (by inhibiting the natural inclination to mimic exactly what the assessor has done). For the present adaptation, children's performance was scored as correct (1) or incorrect (0), with scores averaged across 20 items to represent average executive function skills.

All cognitive assessments underwent an extensive, two-stage adaptation and piloting process prior to full-scale implementation, including psychometric analysis and review by linguistic experts representing each of the seven official languages of Zambia $^{2}$ (see Fink et al., 2012, for details). Cronbach's alpha values were .83 for the receptive language task, an average of .81 across the three non-verbal reasoning tasks, and .84 for executive function. In order to aid in interpretation, all cognitive skill scores were standardized (z-scored) to produce a sample mean of 0 and a standard deviation of 1 for analysis. Bivariate correlations showed statistically significant, positive, low to medium associations between cognitive tasks (see Table 2), indicating that these constructs are related to one another yet represent sufficiently distinct cognitive processes to warrant their simultaneous inclusion in the model of interest.

School enrollment. A binary indicator variable was generated based on caregivers'

\footnotetext{
${ }^{2}$ Three of Zambia's official languages-Kaonde, Luvale and Lunda-are only widely spoken in Northwestern Province. As we did not collect data there due to logistical challenges, out final data set was collected using the Nyanja, Tonga, Bemba, and Lozi versions of the assessment.
} 


\section{POVERTY, HEALTH, AND CHILD DEVELOPMENT}

reports of whether or not the child was enrolled in primary school at the time of the baseline assessment, as well as one year later for children in Cohort 1 only. Given that Zambia's school year starts in January, this variable corresponds to enrollment in school the year the child turns six (for wave 1) and seven (for wave 2). Despite a lack of published consensus regarding the standard age of primary school enrollment in Zambia, we define enrollment at age six as "early" and at age seven as "on time" based on personal communications with government officials.

Covariates. To minimize the risk of confounding biases (e.g., financial strain, differential availability of early education programs, gender-based discrimination), controls for child gender, child age, household size, regional income, and urbanicity were included.

\section{Analytic Plan}

A latent variable structural equation modeling (SEM) framework was used to test the direct and indirect relations between variables of interest outlined in Figure 1. SEM was selected as the analytic method for the present study due to its ability to test multiple processes simultaneously, as well as its ability to provide both absolute and comparative model fit indices. All analyses were conducted in Mplus (version 7) using a WLSMV estimator with a Delta parameterization, which does not assume normal distributions of endogenous variables and is therefore well suited for modeling categorical outcomes (i.e., school enrollment; Brown, 2006; Muthén \& Muthén, 1998-2012). The WLSMV approach has been shown to be an appropriate method for addressing data that are missing at random, conditional on the other variables in the model (Asparouhov \& Muthén, 2010). Most variables in the present study - including covariates - were missing only a small amount of data, with an average missingness of $4.88 \%$. Only one variable, birth month, was missing for a substantial portion of the sample $(34.86 \%)$ due to an administrative error affecting all children in cohort 2 . 
POVERTY, HEALTH, AND CHILD DEVELOPMENT

Across all models, residual correlations were estimated between years of early education and home-based cognitive stimulation, and between the three cognitive skill variables. Standard errors were adjusted using the CLUSTER command to account for children's nesting in the 73 sampling clusters included in this study. In addition to testing direct pathways, exploratory analyses of indirect relations between study variables were evaluated using the MODEL INDIRECT command in Mplus. Embedded measurement models for family wealth, home-based cognitive stimulation, and non-verbal reasoning were included within the overall structural model in order to account for measurement error in combining the 8 wealth items, 3 home-based stimulation items, and 3 non-verbal reasoning tasks, respectively.

To test our primary research questions, several sequential sets of models were compared to identify the best-fitting approach for predicting early school enrollment in the full sample and on-time school enrollment in cohort 1 only. First, beginning with early school enrollment in the full sample, we compared the absolute and relative fit of our full "primary model" outlined in Figure 1 against that of a number of alternative model specifications, including: A) a standard "Western model" of development in which the paths between height-for-age and school enrollment and all other variables were constrained to zero; B) a model in which the paths predicting early investment in learning processes were constrained to zero; C) a model in which paths predicting early investment in learning and height-for-age were constrained to zero; and D) a model in which paths predicting early investment in learning, height-for-age, and cognitive skills were constrained to zero (i.e., a fully direct model in which school enrollment was the exclusive outcome). In particular, Model A was tested to determine whether a traditional model without height-for-age and enrollment may have better represented these data, and Models B through $\mathrm{D}$ were assessed to determine the degree to which a more parsimonious model including 
POVERTY, HEALTH, AND CHILD DEVELOPMENT

fewer paths to outcome variables may have been more appropriate. Criteria for adequate absolute model fit included a root mean square error of approximation (RMSEA) of $<.06$, a confirmatory fit index (CFI) of >.95, and a weighted root mean square residual (WRMR; a variance-weighted fit statistic similar to the SRMR that is appropriate for categorical outcome data) of $<1.0$ (Hu \& Bentler, 1999; Muthén \& Muthén, 1998-2012; Yu, 2002). For nested models, relative model fit was assessed using the DIFFTEST command, which provides a robust chi square difference test with mean and variance adjusted test statistics (Asparouhov \& Muthén, 2006).

Second, we used a two-group cross-validation procedure in which the primary early enrollment model was tested for measurement invariance across two randomly selected split-half subsamples ( $\mathrm{n}=1355$ and 1356) and across the two data collection cohorts $(\mathrm{n}=1766$ and 945 , respectively). To do so, we compared the overall fit of a model in which all parameters were freely estimated across the subsamples against a model in which all parameters were constrained to be equal across subsamples using the DIFFTEST command. Third, we tested the robustness of the primary model predicting early school enrollment in the full sample to the inclusion of a set of covariates (child age, child gender, household size, region wealth, and region urbanicity) on all pathways. Only those covariate pathways that were statistically significant at $p<.10$ were included in the final model in order to conserve statistical power.

Fourth, to understand whether results were similar when predicting on-time - rather than early - school enrollment, we re-estimated the above model for all children who had school enrollment data from one year later, at age seven. As enrollment data at age seven were only collected in cohort 1 due to budgetary constraints, the results of this model cannot be directly compared to the results of the model predicting early school enrollment at age six in the full sample. At the same time, the use of a longitudinal framework in a relatively large sample 
POVERTY, HEALTH, AND CHILD DEVELOPMENT

provides an important opportunity to mitigate concerns that school enrollment at the time of initial study participation may have driven (rather than been driven by) children's height-for-age or cognitive skills.

\section{Results}

Descriptive results. Results of basic descriptive statistics suggest that the average household in the present sample owned approximately three of the seven items on the wealth index (S.D.=2.32). Caregivers reported an average of approximately nine years $($ S.D. $=3.15)$ of education, with $33 \%$ of caregivers reporting the equivalent of a secondary school education or more. Approximately 29 percent of households had children's books and 64 percent had nonchildren's books. About 64 percent of caregivers reported that an adult read to the child in the past week. In total, 34 percent of sample children had ever attended an out-of-home early childhood program. Children's height-for-age and cognitive outcomes were relatively normally distributed, with a mean height-for-age score of -1.01 (S.D=1.17). Approximately 17 percent of the sample was stunted (i.e., showed a height-for-age z-score of more than 2 SDs below the WHO standard). Finally, approximately 17 percent of the full sample was reported to be attending school early at age six, whereas 31 percent of cohort 1 was reported to be attending school on time at age seven. (See Table 1.)

Primary early enrollment model fit and alternative model comparisons. Results of latent variable structural equation models testing our primary theoretical model (see Figure 1) for early enrollment in the full sample indicated adequate fit, with a RMSEA of 0.014 (90\% CI: 0.010-0.018), a CFI of 0.991, and a WRMR of 0.760. Compared to the four alternative models tested, the primary early enrollment model showed the best fit in both absolute and relative terms. (See Table 3.) Specifically, the primary early enrollment model showed significantly 
POVERTY, HEALTH, AND CHILD DEVELOPMENT

better fit compared to: A) the traditional "Western model" of SES, stimulation, and cognitive skills that excluded paths to and from height-for-age and school enrollment, $\operatorname{diff} \chi^{2}(15)=212.985$, $p<.01$, and B) a model in which paths predicting early investment in learning were constrained to be zero, diff $\chi^{2}(4)=176.700, p<.01$. Furthermore, model B) showed significantly better fit than C) a model in which paths predicting early investment in learning and height-for-age were constrained to be zero, diff $\chi^{2}(4)=48.204, p<.01$, and model C) showed significantly better fit than D) a model in which paths predicting early investment in learning, height-for-age, and cognitive skills were constrained to be zero, diff $\chi^{2}(15)=233.615, p<.01$, suggesting that more parsimonious models (i.e., those with fewer direct and indirect paths) were not better suited for representing the present data.

Multiple group comparison. Results revealed equivalent model fit (i.e., a nonsignificant chi-square difference test) across models in the full sample estimating early enrollment in which parameters were freely estimated versus constrained across random subsamples, diff $\chi^{2}(31)=17.840, p=.97$, and cohort, diff $\chi^{2}(31)=35.393, p=.27$. These results suggest that the primary early enrollment model was operating equally well (i.e., was invariant) across randomly selected subsamples of data as well as across data collection cohort. The invariance across cohort, in particular, supports our ability to examine on-time school enrollment in cohort 1 only.

Inclusion of covariates. Next, we included an additional set of covariates (child age, child gender, household size, urbanicity, and regional wealth) predicting each endogenous variable in the early enrollment model in order to account for potentially confounding influences on model parameters. Only those covariate pathways that were statistically significant (at $p<.10)$ were retained in the final early enrollment model. Although the chi-square difference test could 
POVERTY, HEALTH, AND CHILD DEVELOPMENT

not be used to compare the model with and without covariates (as they were non-nested), the chisquare to $d f$ ratio, RMSEA, and TLI of the model with covariates were similar to those of the primary early enrollment model without covariates, indicating comparable - and appropriate fit. (Although the WRMR in the early enrollment model with covariates was higher than the model without covariates, this statistic is less well established and previous work has suggested that it may be ignored when it diverges from other fit statistics; Diemer et al., 2010.)

On-time enrollment model fit. After establishing our early enrollment model in the full sample, we then replicated this model (including covariates) in cohort 1 only using school enrollment data from one year later, at age seven. This final on-time enrollment model showed similar model fit to that of the early enrollment model in the full sample, with a RMSEA of 0.026 (90\% CI: 0.023-0.029), a CFI of 0.942, and a WRMR of 1.267.

\section{Final model results}

Measurement models. Loadings of observed items on latent variables for the embedded measurement models for family wealth, home-based cognitive stimulation, and non-verbal reasoning are presented in Table 4 for both the early and on-time enrollment models. All loadings were statistically significant and in the expected direction.

Direct paths. Direct paths of the final early and on-time enrollment models are shown in Figures 3 and 4, respectively. All direct paths with a $p$-value of $<.10$ are included in the figures and interpreted in text. Children's number of years participating in early education was predicted by family wealth, $b=0.46($ S.E. $=0.09), p<.01$, and maternal education, $b=0.03$ $(\mathrm{S} . \mathrm{E} .=0.02), p<.10$, in the early enrollment model and by family wealth, $b=0.44$ (S.E. $=0.09)$, $p<.01$, only in the on-time enrollment model. Home-based cognitive stimulation was also predicted by both wealth, $b=0.30(\mathrm{~S} . \mathrm{E} .=0.04), p<.01$, and years of maternal education, $b=0.03$ 
POVERTY, HEALTH, AND CHILD DEVELOPMENT

$(\mathrm{S} . \mathrm{E} .=0.01), p<.01$, in the early enrollment model and by wealth, $b=0.29(\mathrm{~S} . \mathrm{E} .=0.05), p<.01$, only in the on-time enrollment model. Height-for-age was directly predicted by years of early education, $b=0.07$ (S.E. $=0.02), p<.05$, and home-based cognitive stimulation, $b=0.12$ $(\mathrm{S} . \mathrm{E} .=0.05), p<.05$, in the early enrollment model, and only by home-based cognitive stimulation, $b=0.14$ (S.E. $=0.09), p<.10$, in the on-time model.

Children's language skills were directly predicted by family wealth, $b=0.23$ (S.E. $=0.06)$, $p<.01$, maternal education, $b=0.04$ (S.E. $=0.01), p<.01$, home-based cognitive stimulation, $b=0.13$ $(\mathrm{S} . \mathrm{E} .=0.06), p<.05$, and height-for-age, $b=0.13$ (S.E. $=0.02), p<.01$, in the early enrollment model, and wealth, $b=0.26$ (S.E. $=0.08), p<.01$, maternal education, $b=0.04$ (S.E. $=0.01), p<.01$, and height-for-age, $b=0.09$ (S.E. $=0.03), p<.01$, in the on-time model. The non-verbal reasoning latent variable was directly predicted by family wealth, $b=0.11$ (S.E. $=0.05), p<.05, p<.01$, homebased cognitive stimulation, $b=0.18$ (S.E. $=0.06), p<.01$, and height-for-age, $b=0.06$ (S.E. $=0.02$ ), $p<.01$, in the early model and by family wealth, $b=0.13$ (S.E. $=0.06$ ), $p<.05$, years of early education, $b=0.04$ (S.E. $=0.02), p<.10$, and home-based cognitive stimulation, $b=0.15$ $($ S.E. $=0.08), p<.10$, in the on-time model. Executive function was directly predicted by years of early education, $b=0.04$ (S.E. $=0.02$ ), $p<.01$, home-based cognitive stimulation, $b=0.25$ (S.E. $=0.07), p<.01$, and height-for-age, $b=0.10(\mathrm{~S} . \mathrm{E} .=0.03), p<.01$, in the early model, and by years of early education, $b=0.09$ (S.E. $=0.03$ ), $p<.01$, and home-based cognitive stimulation, $b=0.25(\mathrm{~S} . \mathrm{E} .=0.08), p<.01$, in the on-time model.

Finally, early school enrollment at age six was directly predicted by years of early education, $b=0.13$ (S.E. $=0.03$ ), $p<.01$, at-home stimulation, $b=0.13$ (S.E. $=0.08), p<.10$, heightfor-age, $b=0.25$ (S.E. $=0.05), p<.01$, and executive function skills, $b=0.13$ (S.E. $=0.05), p<.05$. (These results can be contrasted with those of the poorer fitting Model D, which excluded 
POVERTY, HEALTH, AND CHILD DEVELOPMENT

indirect pathways and showed significant, positive relations between all exogenous predictor variables and early school enrollment, including family wealth, $b=0.27$ [S.E. $=0.08], p<.01$, and maternal education, $b=0.04$ [S.E. $=0.01], p<.01$.) In the final model, on-time enrollment at age seven was directly predicted by the same variables - years of early education, $b=0.11$

$(\mathrm{S} . \mathrm{E} .=0.04), p<.01$, at-home stimulation, $b=0.23(\mathrm{~S} . \mathrm{E} .=0.09), p<.05$, height-for-age, $b=0.11$ $(\mathrm{S} . \mathrm{E} .=0.05), p<.05$, and executive function skills, $b=0.20(\mathrm{~S} . \mathrm{E} .=0.06), p<.01-$ as well as family wealth, $b=-0.21$ (S.E. $=0.12), p<.10$, maternal education, $b=0.03$ (S.E. $=0.02), p<.10$, and nonverbal reasoning, $b=0.33(\mathrm{~S} . \mathrm{E} .=0.14), p<.01$, in the cohort 1 sample only.

Indirect paths. Coefficients for all significant indirect pathways for both the early and on-time enrollment models are presented in Table 5. Given the number of tested pathways and significant results, only those indirect pathways that achieved a significance level of $p<.01$ are highlighted below. In the early enrollment model, we observed a significant indirect path from household wealth to height-for-age via years of early childhood education, $b=0.034$ (S.E. $=0.012), p<.01$. This indirect pathway was also significant when extended to include children's language scores, $b=0.004($ S.E. $=0.001), p<.01$. Wealth was also significantly predictive of early school enrollment via early childhood education, $b=0.061$ (S.E. $=0.016$ ), $p<.01$, and early childhood education was significantly predictive of early school enrollment via height-for-age, $b=0.019(0.006), p<.01$. Indirect pathways from wealth via home-based cognitive stimulation were also predictive of both non-verbal reasoning, $b=0.052$ (S.E. $=0.019)$, $p<.01$, and executive function, $b=0.075$ (S.E. $=0.020), p<.01$, in the early enrollment model. The only two indirect pathways that were significant at $p<.01$ for the on-time enrollment model were between wealth and executive function via early childhood education, $b=0.041$ (S.E. $=0.015$ ), $p<.01$, and via at-home cognitive stimulation, $b=0.071(\mathrm{~S} . \mathrm{E} .=0.023), p<.01$. 


\section{POVERTY, HEALTH, AND CHILD DEVELOPMENT}

\section{Discussion}

The primary goal of the present study was to present an adapted model of socioeconomic status, early exposure to stimulating learning environments, and child cognitive skills, and to test this model's validity within a sample of Zambian children facing levels of poverty, malnutrition, and educational barriers similar to those of many LMICs. As such, this study was conceived as an initial effort to extend and adapt existing Western models of child development for use in a sub-Saharan African, low-income country. Results of this study revealed that although the strength of the associations vary, the relationships between SES, parental stimulation, and cognitive skills previously observed in high-income countries appear to hold true in the Zambian context, as well (Duncan \& Brooks-Gunn, 2000; Gershoff et al., 2007; Guo \& Harris, 2000; Lugo-Gil \& Tamis-LeMonda, 2008; McLoyd, 1998). In particular, material resources in children's homes and levels of caregiver education were both directly predictive of the number of years children spent enrolled in an early childhood education program and home-based reading materials and activities in the full sample using cross-sectional data.

As with past research from the U.S. (e.g., Duncan, Brooks-Gunn, \& Klebanov, 1994; Magnuson, Sexton, Davis-Kean, \& Huston, 2009), results of our models suggest that household wealth may be a particularly strong predictor of non-verbal dimensions of cognition (i.e., reasoning and executive function) both directly and indirectly through home-based stimulation, whereas maternal education may relate more strongly and directly with children's language. Interestingly, although home-based stimulation was directly predictive of all three dimensions of cognition in the full early enrollment sample, early childhood education participation was directly associated only with children's executive function. Given that past research from the U.S. has shown impacts of early childhood program participation on a diverse range of cognitive 
POVERTY, HEALTH, AND CHILD DEVELOPMENT

skills of low-income children (e.g., NICHD Early Child Care Research Network, 2002; Ramey et al., 2000), additional research is needed to explore potential reasons for these discrepancies, including, for example, differences in the intensity, goals, and quality of Zambian early childhood centers.

In addition to replicating these basic relations, our results suggest that the importance of SES for Zambian children's cognitive skills is likely further amplified through the mechanism of child physical stature, a variable that is infrequently explored in more affluent countries where physical stunting is rare. Results of our cross-sectional early enrollment model in our full sample suggest that in Zambia, where exposure to infectious disease and malnutrition in early childhood are high and public health, water, and sanitation services are limited, maternal education and household wealth may serve as protective factors for children's physical stature via their relationships with home-based stimulation and early childhood program enrollment. In addition to the direct nutritional benefits that may be provided to children attending early childhood centers (which often include daily feeding programs and health-related services), these relations likely reflect the greater (unobserved) capacities of high-SES caregivers to invest in the noncognitive development and growth of their children. Additional research is needed to test this specific hypothesis, as well as to understand why SES and early childhood education appear to play a substantially less important role in predicting physical stature within the longitudinal model predicting children's school enrollment at age seven.

Results of the early enrollment model in the full sample also suggest that children's physical stature (a proxy for early childhood health-related adversity and malnutrition) directly predicts their language, non-verbal reasoning, and executive function skills above and beyond their early experiences of SES and early learning. This finding was replicated for the on-time 
POVERTY, HEALTH, AND CHILD DEVELOPMENT

enrollment model in the more limited sample, but only for children's language skills. Although these results provide initial support for a causal relation between early health-related adversity and cognition (e.g., where the biological burdens of malnutrition or infectious disease manifest as reductions in both physical stature and brain functioning) (Grantham-McGregor et al., 2007), further research is needed using causally valid methodology and longitudinal datasets to fully establish the relative contributions of biological and (confounding) environmental underpinnings of this relationship.

An additional goal of the present study was to extend the existing model of child cognition to identify predictors of children's early and on-time school enrollment, which serve as important indicators of later schooling and economic outcomes that are often excluded from Western frameworks due to government mandates in these contexts that standardize and enforce age of enrollment for young children. Understanding the processes that lead to both early and timely school enrollment is critical for developing policies that support Zambian children's entry into school. The results of both of our final models suggest three sets of predictors of school enrollment at ages six and seven. First, children's height-for-age at age six was significantly predictive of enrollment both concurrently and one year later, suggesting that caregivers (or primary school teachers) may be making decisions about school readiness largely based on their children's physical size. Delaying school enrollment for small children - who our results suggest are also more at risk in other domains - may exacerbate disparities by reducing the opportunities for these children to catch up to their peers both cognitively and physically through the government supported mechanism of primary education.

Second, executive function was also strongly related to school enrollment in both sets of models: children who followed a stranger's instructions, inhibited impulsive responses, and paid 
POVERTY, HEALTH, AND CHILD DEVELOPMENT

attention over a span of time were more likely to be enrolled in school than their impulsive or inattentive peers. This finding mirrors past work in the United States showing the importance of children's early executive function skills for their later school outcomes (Blair \& Razza, 2007). Although neither language nor non-verbal skills were predictive of early school enrollment, we did find that early non-verbal reasoning skills (as measured using a set of pattern recognition tasks) was predictive of on-time school enrollment in our longitudinal model. Additional work is needed to understand the relations between executive function, non-verbal reasoning, and enrollment, as well as why these particular cognitive skills may be markers of school readiness more so than language in the Zambian context.

Third, our results reveal that early school enrollment was directly predicted by exposure to home- and center-based early learning experiences, as well as indirectly through household wealth's relationship with center-based stimulation. Our model examining on-time school enrollment at age seven also supported the direct relationships between both dimensions of SES and timely enrollment, above and beyond other characteristics in the model. Collectively, these findings suggest that family resources and investments in children's learning appear to be independently important for predicting children's enrollment in school, above and beyond children's perceived school readiness.

Together, these findings have several potential implications for policy and practice. From an educational or social welfare perspective, our results suggest that the socioeconomic gradient in child cognitive skills may be larger in Zambia than in high-income countries today; it also suggests that for Zambian children, a non-negligible portion of cognitive inequalities and enrollment disparities can be directly attributed to early childhood learning and physical stature, both of which can be fundamentally addressed and altered by suitable public policies. As a result 
POVERTY, HEALTH, AND CHILD DEVELOPMENT

of a collection of broader efforts associated with the Millennium Development Goals, major progress has been made over the past 20 years in the availability and efficacy of programs to support child health and nutrition (de Onis, Blossner, \& Borghi, 2012; Maternal and Child Health Nutrition Study Group, 2013). With respect to early childhood education and care, however, relatively few structured, center-based, or widespread government-provided programs are available in LMICs today. Although the cost of creating a network of high-quality early childhood education centers that can reach all children would be challenging for Zambia and other LMICs, this finding suggests the need for countries' investments in children's early educational experiences - both home- and community-based - as a means of potentially boosting health, cognition, and school enrollment. Existing antenatal and early infancy programs, which are currently relatively widespread, may offer a low-cost opportunity for community health workers to begin discussions with expectant mothers (who may have older children, as well) on the importance providing stimulating environments for children and enrolling children in school at the appropriate time, regardless of physical size (Yousafzai, Rasheed, Rizvi, Armstrong, \& Bhutta, 2014). Furthermore, a simple policy directive that could be taken immediately would be to formalize and publicize the official school starting age (e.g., an announcement from the Ministry of Education that all children turning six in a given year must be enrolled in school by January of the following year). Although such a directive may not result in total compliance, it would reduce the complexity of the decision-making process for caregivers and potentially reduce long-term differences in educational outcomes that result from initial disparities in SES.

\section{Limitations}

Although this study provides several important contributions to the existing literature on early childhood outcomes in the context of low SES, there are several limitations to this work 
POVERTY, HEALTH, AND CHILD DEVELOPMENT

that we would like to acknowledge. First, the omission of age in months from the survey in the second cohort limits the precision with which we were able to calculate height-for-age for the early enrollment models in approximately one third of the sample. Although sensitivity analyses revealed only minimal differences in results when excluding children with missing age data, the method chosen to mitigate this issue (estimating age in cohort 2) likely introduced error in the model that may have biased results in unknowable ways.

Second, the vast majority of the variables used in the present study were collected concurrently, which precludes causal attributions of identified relations. It is possible, for example, in the early enrollment model that children's enrollment in school actually lead to increases in their nutritional intake (e.g., through school feeding programs), improvements in cognitive functioning, and/or increased likelihood of caregivers spending time with children on cognitively stimulating activities in the home. Although we mitigate some of these concerns through testing an additional model of on-time enrollment at age seven, we are still unable to establish causality, particularly with regard to the relations between SES, investment, physical stature, and cognition. Future studies are needed that provide longitudinal data collected at additional time points, as well as experimental tests of interventions that target specific parts of the model (i.e., family income supplementation, caregiver education, publicly funded early childhood education programming, caregiver education for at-home stimulation).

Third, though we discuss this study as a test of whether Western-developed models apply in a LMIC, we must note that the Zambian context is not representative of all other LMIC contexts. Although Zambia shares many characteristics with other countries in the region (e.g., high rates of poverty, illiteracy, and disease compared to developed nations), results of this study are not necessarily applicable to other countries due to significant cultural, policy, and contextual 
POVERTY, HEALTH, AND CHILD DEVELOPMENT

differences. In fact, we feel strongly that future studies in other countries and parts of the world are critical for addressing the question of whether the relations between poverty, child health, and child development are universal or context-specific.

Finally, although many of the measures used in the present study are commonly used in resource-limited settings, additional research is needed to provide more targeted and nuanced representations of these developmental processes in Zambia and other LMICs. Cognitive stimulation, for example, can be provided in multiple ways other than reading to a child or providing him/her with books. Exploring the ways that caregivers from different cultures and contexts optimize their children's learning ways is a critical area of needed research.

\section{Conclusions}

The present study evaluated an adapted model of early childhood cognition in the modern developing country context of Zambia, featuring types and levels of socioeconomic adversity very different from the Western context generally studied in the literature. Results of this study revealed three important conclusions. First, previous models identifying early exposure to cognitive stimulation as a key mediator between household poverty and children's cognitive outcomes appear to be valid within the Zambian context, taking into account modifications to traditional, U.S. definitions of these constructs. Second, the inclusion of children's physical stature as a proxy for exposure to early health and nutrition appears to be a core pathway in explaining the relations between household socioeconomic status and children's cognitive skills. Third, physical stature, executive function, non-verbal reasoning, and exposure to resource-rich, stimulating learning environments appear to be important predictors of Zambian children's early and on-time enrollment in school. These results not only serve as a preliminary step in extending the theoretical frameworks of child development to a global context, but also suggest several 


\section{POVERTY, HEALTH, AND CHILD DEVELOPMENT}

important targets for early intervention to promote cognitive skills and timely primary school

enrollment. Future research is needed to better quantify the causal pathways hypothesized by this model, as well as to better understand how these processes may operate in diverse cultural and socioeconomic contexts across the world. 
POVERTY, HEALTH, AND CHILD DEVELOPMENT

\section{References}

Aburto, N. J., Ramirez-Zea, M., Neufeld, L. M., \& Flores-Ayala, R. (2009). Some indicators of nutritional status are associated with activity and exploration in infants at risk for vitamin and mineral deficiencies. Journal of Nutrition, 139(9), 1751-1757. doi:

10.3945/jn.108.100487

Adair, L. S., Fall, C. H. D., Osmond, C., Stein, A. D., Martorell, R., Ramirez-Zea, M., .. . Victora, C. G. (2013). Associations of linear growth and relative weight gain during early life with adult health and human capital in countries of low and middle income: findings from five birth cohort studies. The Lancet, 382(9891), 525-534. doi: 10.1016/S0140$6736(13) 60103-8$

Angrist, J. D., \& Krueger, A. B. (1992). The effect of age at school entry on educational attainment: An application of instrumental variables with moments from two samples. Journal of the American Statistical Association, 87(418), 328-336. doi:

$10.1080 / 01621459.1992 .10475212$

Asparouhov, T., \& Muthén, B. (2006). Robust chi square difference testing with mean and adjusted test statistics. In Mplus web notes (p. 9). Los Angeles: University of California Los Angeles.

Asparouhov, T., \& Muthén, B. (2010). Weighted least squares estimation with missing data. MplusTechnical Appendix.

Blair, C., \& Raver, C. C. (2012). Child development in the context of adversity: Experiential canalization of brain and behavior. American Psychologist, 67(4), 309-318. doi: $10.1037 / \mathrm{a} 0027493$

Blair, C., \& Razza, R. P. (2007). Relating effortful control, executive function, and false belief 
POVERTY, HEALTH, AND CHILD DEVELOPMENT

understanding to emerging math and literacy ability in kindergarten. Child Development, 78(2), 647-663. doi: 10.1111/j.1467-8624.2007.01019.x

Brown, T. (2006). Confirmatory factor analysis for applied research. New York: Guildford.

Buchmann, C. (2000). Family structure, parental perceptions, and child labor in Kenya: What factors determine who is enrolled in school? Social Forces, 78(4), 1349-1378. doi:

Burchinal, M. R., Campbell, F. A., Bryant, D. M., Wasik, B. H., \& Ramey, C. T. (1997). Early intervention and mediating processes in cognitive performance of children of low-income African American families. Child Development, 68(5), 935-954. doi: 10.2307/1132043

Central Statistical Office of Zambia and Macro International Inc. (2009). Zambia Demographic and Health Survey 2007: Key findings. Calverton, MD: CSO and Macro International Inc.

Daniels, M. C., \& Adair, L. (2004). Growth in young Filipino children pedicts schooling trajectories through high school. Journal of Nutrition, 134(6), 1439-1446.

Davis-Kean, P. E. (2005). The influence of parent education and family income on child achievement: the indirect role of parental expectations and the home environment. Journal of Family Psychology, 19(2), 294-304. doi: 10.1037/0893-3200.19.2.294

de Onis, M., Blossner, M., \& Borghi, E. (2012). Prevalence and trends of stunting among preschool children, 1990-2020. Public Health and Nutrition, 15(1), 142-148. doi: $10.1017 / \mathrm{s} 1368980011001315$

de Onis, M., Onyango, A., Borghi, E., Siyam, A., Nishida, C., \& Siekmann, J. (2007). Development of a WHO growth reference for school-aged children and adolescents. Bulletin of the World Health Organization, 85, 661-668. doi: 10.2471/BLT.07.043497 Dewey, K. G., \& Begum, K. (2011). Long-term consequences of stunting in early life. Maternal 
POVERTY, HEALTH, AND CHILD DEVELOPMENT

and Child Nutrition, 7(s3), 5-18. doi: 10.1111/j.1740-8709.2011.00349.x

Dhongde, S., \& Minoiu, C. (2013). Global poverty estimates: A sensitivity analysis. World Development, 44(0), 1-13. doi: http://dx.doi.org/10.1016/j.worlddev.2012.12.010

Diemer, M. A., Wang, Q., Moore, T., Gregory, S. R., Hatcher, K. M., \& Voight, A. M. (2010). Sociopolitical development, work salience, and vocational expectations among low socioeconomic status African American, Latin American, and Asian American youth. Developmental Psychology, 46(3), 619-635. doi: 10.1037/a0017049

Duncan, G. J., \& Brooks-Gunn, J. (2000). Family poverty, welfare reform, and child development. Child Development, 71(1), 188-196. doi: 10.1111/1467-8624.00133

Duncan, G. J., Brooks-Gunn, J., \& Klebanov, P. K. (1994). Economic deprivation and early childhood development. Child Development, 65(2), 296-318. doi: 10.2307/1131385

Duncan, G. J., Dowsett, C. J., Claessens, A., Magnuson, K., Huston, A. C., Klebanov, P., . . . Duckworth, K. (2007). School readiness and later achievement. Developmental Psychology, 43(6), 1428-1446. doi: 10.1037/0012-1649.43.6.1428

Dunn, L. M., \& Dunn, L. M. (1997). Peabody Picture Vocabulary Test III. Circle Pines, MN: American Guidance Service.

Engle, P. L., Fernald, L. C., Alderman, H., Behrman, J., O'Gara, C., Yousafzai, A., ... \& Iltus, S. (2011). Strategies for reducing inequalities and improving developmental outcomes for young children in low-income and middle-income countries. The Lancet, 378(9799), 1339-1353. doi: 10.1016/S0140-6736(11)60889-1

Fawcett, C., Hartwell, A., \& Israel, R. (2010). Out-of-school youth in developing countries: What the data do (and do not) tell us. Washington, D.C.: USAID.

Fentiman, A., Hall, A., \& Bundy, D. (2001). Health and cultural factors associated with 


\section{POVERTY, HEALTH, AND CHILD DEVELOPMENT}

enrolment in basic education: a study in rural Ghana. Social Science \& Medicine, 52, 429-439. doi: 10.1016/S0277-9536(00)00152-0

Filmer, D., \& Pritchett, L. H. (2001). Estimating wealth effects without expenditure data--or tears: An application to educational enrollments in states of India. Demography, 38(1), 115-132. doi: 10.1353/dem.2001.0003

Fink, G., Matafwali, B., Moucheraud, C., \& Zuilkowski, S. S. (2012). The Zambian Early Childhood Development Project: 2010 Assessment Final Report. Cambridge, MA: Harvard University.

Fink, G., Zuilkowski, S. S., \& Matafwali, B. (2011). The Zambian Early Childhood Development Project : Round I Final Report. Cambridge, MA: Harvard University.

Gardner, J. M., Grantham-McGregor, S. M., Himes, J., \& Chang, S. (1999). Behaviour and development of stunted and nonstunted Jamaican children. Journal of Child Psychology and Psychiatry, 40(5), 819-827. doi:10.1111/1469-7610.00497

Gershoff, E. T., Aber, J. L., Raver, C. C., \& Lennon, M. C. (2007). Income is not enough: Incorporating material hardship into models of income associations with parenting and child development. Child Development, 78(1), 70-95. doi: 10.1111/j.14678624.2007.00986.x

Glewwe, P., \& Jacoby, H. G. (1995). An economic analysis of delayed primary school enrollment in a low income country: The role of early childhood nutrition. Review of Economics and Statistics, 77(1), 156-169. doi: 10.2307/2110001

Grantham-McGregor, S., Cheung, Y. B., Cueto, S., Glewwe, P., Richter, L., Strupp, B., \& International Child Development Steering Group. (2007). Developmental potential in the first 5 years for children in developing countries. Lancet, 369(9555), 60-70. doi: 
POVERTY, HEALTH, AND CHILD DEVELOPMENT

$10.1016 / \mathrm{S} 0140-6736(07) 60032-4$

Grogan, L. (2009). Universal primary education and school entry in Uganda. Journal of African Economies, 18(2), 183-211. doi: 10.1093/jae/ejn015

Guo, G., \& Harris, K. M. (2000). The mechanisms mediating the effects of poverty on children's intellectual development. Demography, 37(4), 431-447. doi: 10.1353/dem.2000.0005

Gutman, L. M., Sameroff, A. J., \& Cole, R. (2003). Academic growth curve trajectories from 1st grade to 12th grade: Effects of multiple social risk factors and preschool child factors. Developmental Psychology, 39, 777-790. doi: 10.1037/0012-1649.39.4.777

Hoff, E. (2003). The specificity of environmental influence: Socioeconomic status affects early vocabulary development via maternal speech. Child Development, 74(5), 1368-1378. doi: $10.1111 / 1467-8624.00612$

Hu, L. t., \& Bentler, P. M. (1999). Cutoff criteria for fit indexes in covariance structure analysis: Conventional criteria versus new alternatives. Structural Equation Modeling: A Multidisciplinary Journal, 6(1), 1-55. doi: 10.1080/10705519909540118

Kaufman, A. S. (2004). Kaufman Assessment Battery for Children-II (KABC-II). Circle Pines, MN: American Guidance Service.

Korkman, M., Kirk, U., \& Kemp, S. (1998). NEPSY: A developmental neuropsychological assessment. San Antonio, TX: Psychological Corporation.

Lloyd, C. B., \& Mensch, B. S. (2000). The effects of primary school quality on school dropout among Kenyan boys and girls. Comparative Education Review, 44(2), 113-147. doi: $10.1086 / 447600$

Lozano, R., Naghavi, M., Foreman, K., Lim, S., Shibuya, K., Aboyans, V., . . Murray, C. J. (2013). Global and regional mortality from 235 causes of death for 20 age groups in 1990 


\section{POVERTY, HEALTH, AND CHILD DEVELOPMENT}

and 2010: a systematic analysis for the Global Burden of Disease Study 2010. Lancet, 380(9859), 2095-2128. doi: 10.1016/s0140-6736(12)61728-0

Lugo-Gil, J., \& Tamis-LeMonda, C. S. (2008). Family resources and parenting quality: links to children's cognitive development across the first 3 years. Child Development, 79(4), 1065-1085. doi: 10.1111/j.1467-8624.2008.01176.x

Magnuson, K. A., Sexton, H. R., Davis-Kean, P. E., \& Huston, A. C. (2009). Increases in maternal education and young children's language skills. Merrill-Palmer Quarterly, 55(3), 319-350. doi: 10.1353/mpq.0.0024

Maternal and Child Health Nutrition Study Group. (2013). Maternal and child undernutrition and overweight in low-income and middle-income countries. Lancet, 382, 427-451. doi: 10.1016/S0140-6736(13)60937-X

McLoyd, V. C. (1998). Socioeconomic disadvantage and child development. American Psychologist, 53(2), 185-204. doi: 10.1037//0003-066X.53.2.185

Morris, P. A., \& Gennetian, L. A. (2003). Identifying the Effects of Income on Children's Development Using Experimental Data. Journal of Marriage and Family, 65(3), 716729. doi: $10.2307 / 3600034$

Muthén, L. K., \& Muthén, B. O. (1998-2012). Mplus user's guide (7th ed.). Los Angeles, CA: Muthén \& Muthén.

NICHD Early Child Care Research Network. (2002). Early child care and children's development prior to school entry: Results from the NICHD Study of Early Child Care. American Educational Research Journal, 39(1), 133-164. doi: $10.3102 / 00028312039001133$

Partnership for Child Development. (1999). Short stature and the age of enrolment in primary 


\section{POVERTY, HEALTH, AND CHILD DEVELOPMENT}

school: Studies in two African countries. Social Science \& Medicine, 48, 675-682. doi: $10.1016 / \mathrm{S} 0277-9536(98) 00382-7$

Piper, B., Jukes, M. C. H., \& Miguel, E. (in prep). Crossing the divide: Increasing inequalities in upper primary school completion and secondary enrollment for girls and the poor in Kenya.

Ramey, C. T., Campbell, F. A., Burchinal, M., Skinner, M. L., Gardner, D. M., \& Ramey, S. L. (2000). Persistent effects of early childhood education on high-risk children and their mothers. Applied Developmental Science, 4(1), 2-14. doi:

10.1207/S1532480XADS0401_1

Republic of Zambia. (2012). Zambia country report: Monitoring the Declaration of Commitment on HIV and AIDS and the universal access. Lusaka: Republic of Zambia.

Sameroff, A. J., Seifer, R., Barocas, R., Zax, M., \& Greenspan, S. (1987). Intelligence quotient scores of 4-year-old children: Social-environmental risk factors. Pediatrics, 79(3), 343350.

Schafer, M. J. (2006). Household change and rural school enrollment in Malawi and Kenya. The Sociological Quarterly, 47(4), 665-691. doi: 10.1111/j.1533-8525.2006.00062.x

Sirin, S. R. (2005). Socioeconomic status and academic achievement: A meta-analytic review of research. Review of Educational Research, 75(3), 417-453. doi:

$10.3102 / 00346543075003417$

Smith-Donald, C., Raver, C. C., \& Hayes, T. (2007). Preliminary construct and concurrent validity of the Preschool Self-regulation Assessment (PSRA) for field-based research. Early Childhood Research Quarterly, 22(2), 173-187. doi:10.1016/j.ecresq.2007.01.002

The African Economist. (2013, July 6). Ranking of African countries by literacy rate: Zimbabwe 
POVERTY, HEALTH, AND CHILD DEVELOPMENT

No. 1. from http://theafricaneconomist.com/ranking-of-african-countries-by-literacy-ratezimbabwe-no-1/

UNESCO. (2012). EFA Global Monitoring Report. Paris: UNESCO.

UNICEF. (2013). UNICEF Zambia fact sheet: Early childhood development. from http://www.unicef.org/zambia/5109 8463.html

United Nations. (2013). The Millennium Development Goals Report. New York: Author.

United Nations. (2014). The Millennium Development Goals Report. New York: Author.

United Nations Development Programme. (2014). Sustaining human progress: Reducing vulnerability and building reslience. Washington, DC: Author.

Walker, S., Chang, S., Powell, C., Simonoff, E., \& Grantham-McGregor, S. (2007 ). Early childhood stunting is associated with poor psychological functioning in late adolescence and effects are reduced by psychosocial stimulation. Journal of Nutrition, 137(11), 24642469.

Wang, H., Dwyer-Lindgren, L., Lofgren, K., Rajaratnam, J., Marcus, J., Levin-Rector, A., . . . Murray, C. (2012). Age-specific and sex-specific mortality in 187 countries, 1970-2010: A systematic analysis for the Global Burden of Disease Study 2010. Lancet, 380(9859), 2071-2094. doi: 10.1016/S0140-6736(12)61719-X

WHO. (2006). Anthro Software for assessing growth and development of the world's children. Geneva: WHO.

World Bank. (2013). Public spending on education. from http://data.worldbank.org/indicator/SE.XPD.TOTL.GD.ZS

Yeung, W. J., Linver, M. R., \& Brooks-Gunn, J. (2002). How money matters for young children's development: Parental investment and family processes. Child 
POVERTY, HEALTH, AND CHILD DEVELOPMENT

Development, 73(6), 1861-1879. doi: 10.1111/1467-8624.t01-1-00511

Yousafzai, A., Rasheed, M.A., Rizvi, A., Armstrong, R., Bhutta, Z. A. (2014). Effect of integrated responsive stimulation and nutrition interventions in the Lady Health Worker programme in Pakistan on child development, growth, and health outcomes: a clusterrandomised factorial effectiveness trial. Lancet, 384(9950), 1282-1293. doi: $10.1016 / \mathrm{S} 0140-6736(14) 60455-4$

Yu, C. Y. (2002). Evaluating cutoff criteria of model fit indices for latent variable models with binary and continuous outcomes. Doctoral dissertation. Los Angeles: University of California.

Zuilkowski, S. S., Fink, G., Moucheraud, C., \& Matafwali, B. (2012). Early childhood education, child development and school readiness: Evidence from Zambia. South African Journal of Childhood Education, 2(2), 117-136. 


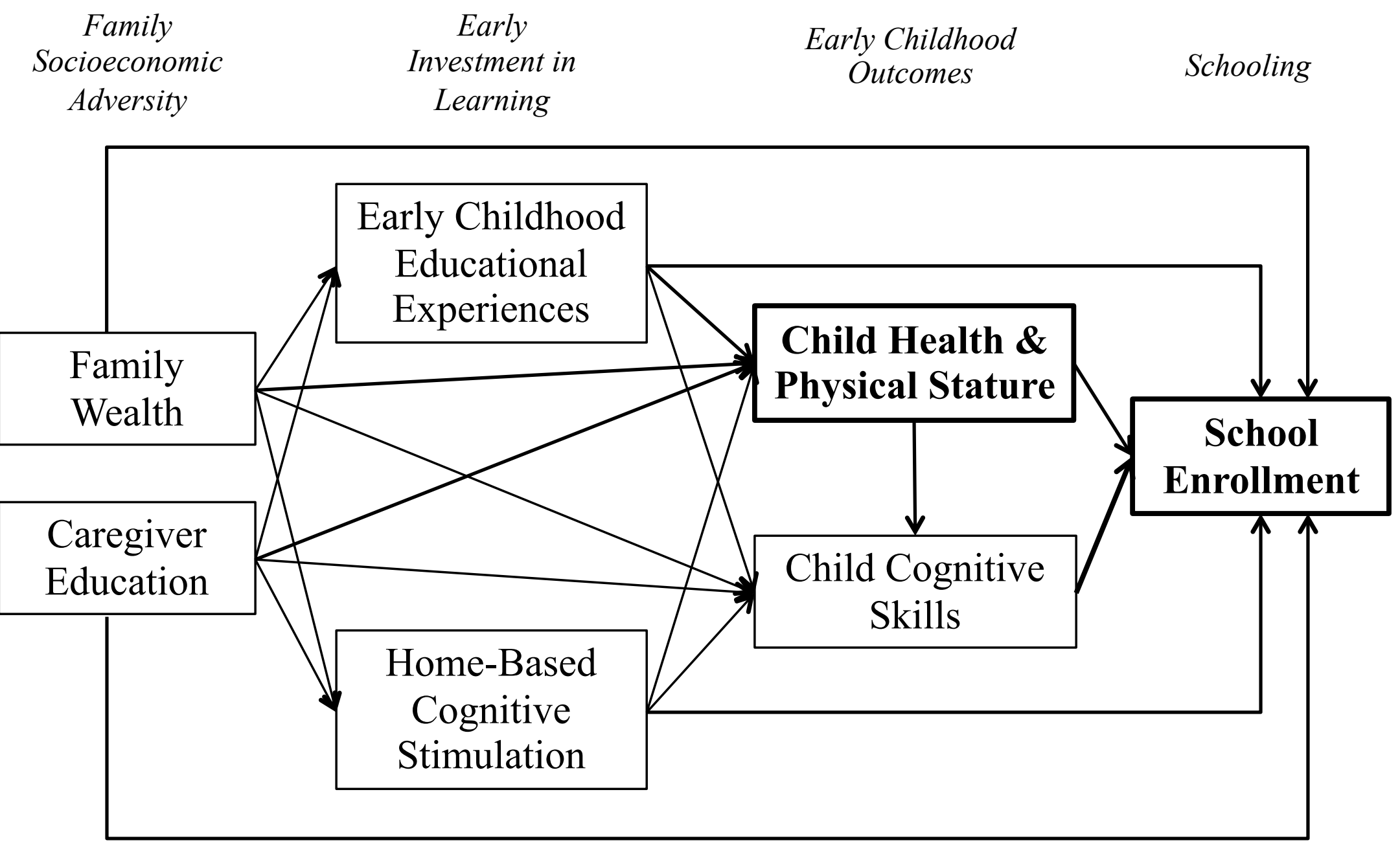

Figure 1. Proposed theoretical model of the relations between family SES, early investment in learning, child development, and schooling in low- and middle-income countries. Bold variables and paths indicate unique contributions over previous models of early development from the United States. 
POVERTY, HEALTH, AND CHILD DEVELOPMENT

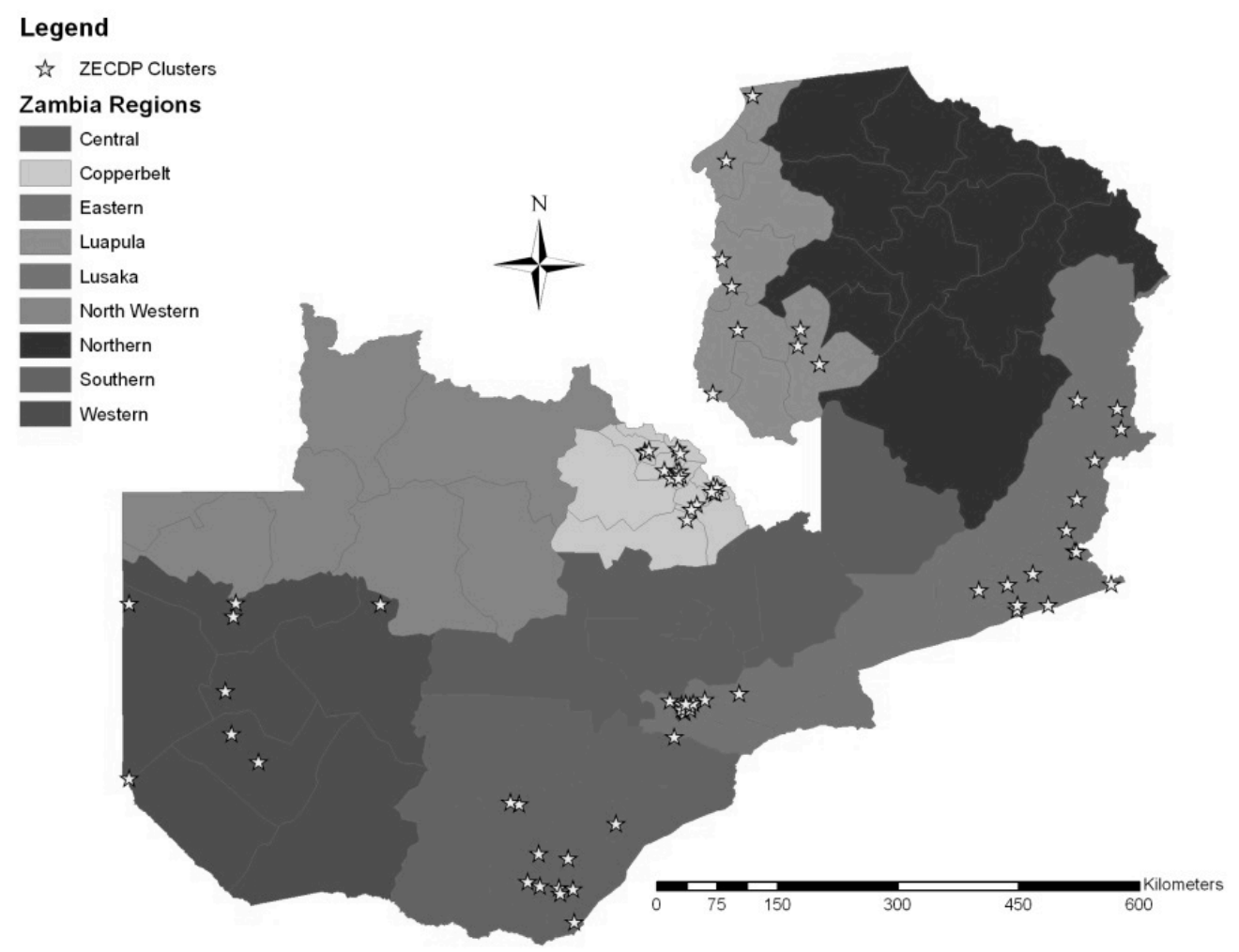

Figure 2. Zambia Early Childhood Development Project study areas (sample clusters). 


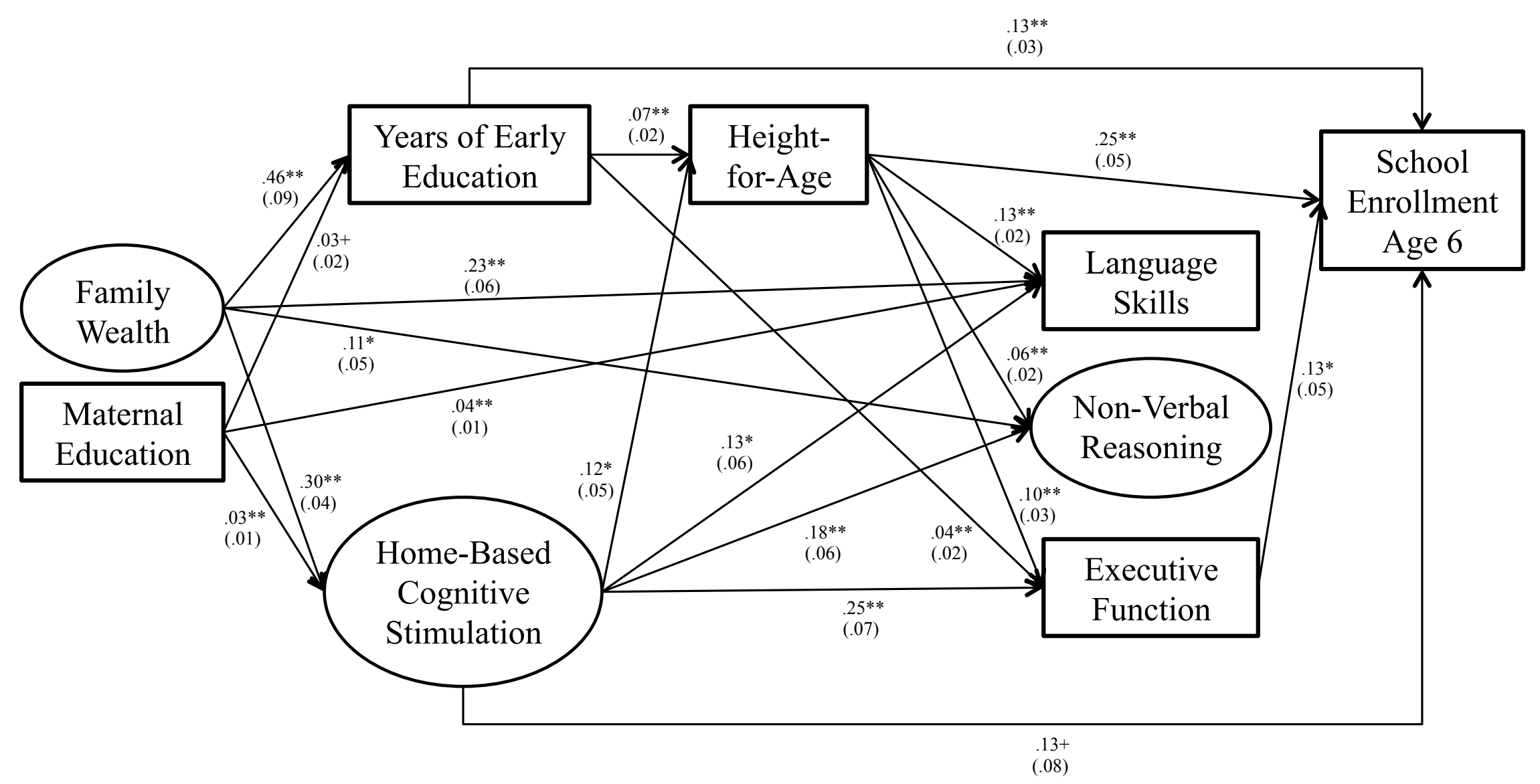

Figure 3. Final early (age 6) enrollment structural equation model results (Full sample; n=2711)

Notes: $+p<.10, * p<.05, * * p<.01$. Only significant, direct pathways shown. See Table 5 for coefficients and standard errors of significant indirect pathways. Covariates (child gender, child age, household size, region urbanicity, region wealth), residual correlations (between cognitive stimulation variables, and between cognitive skill variables), and embedded measurement models (for family wealth, home-based cognitive stimulation, and non-verbal reasoning) included in model but not shown. 


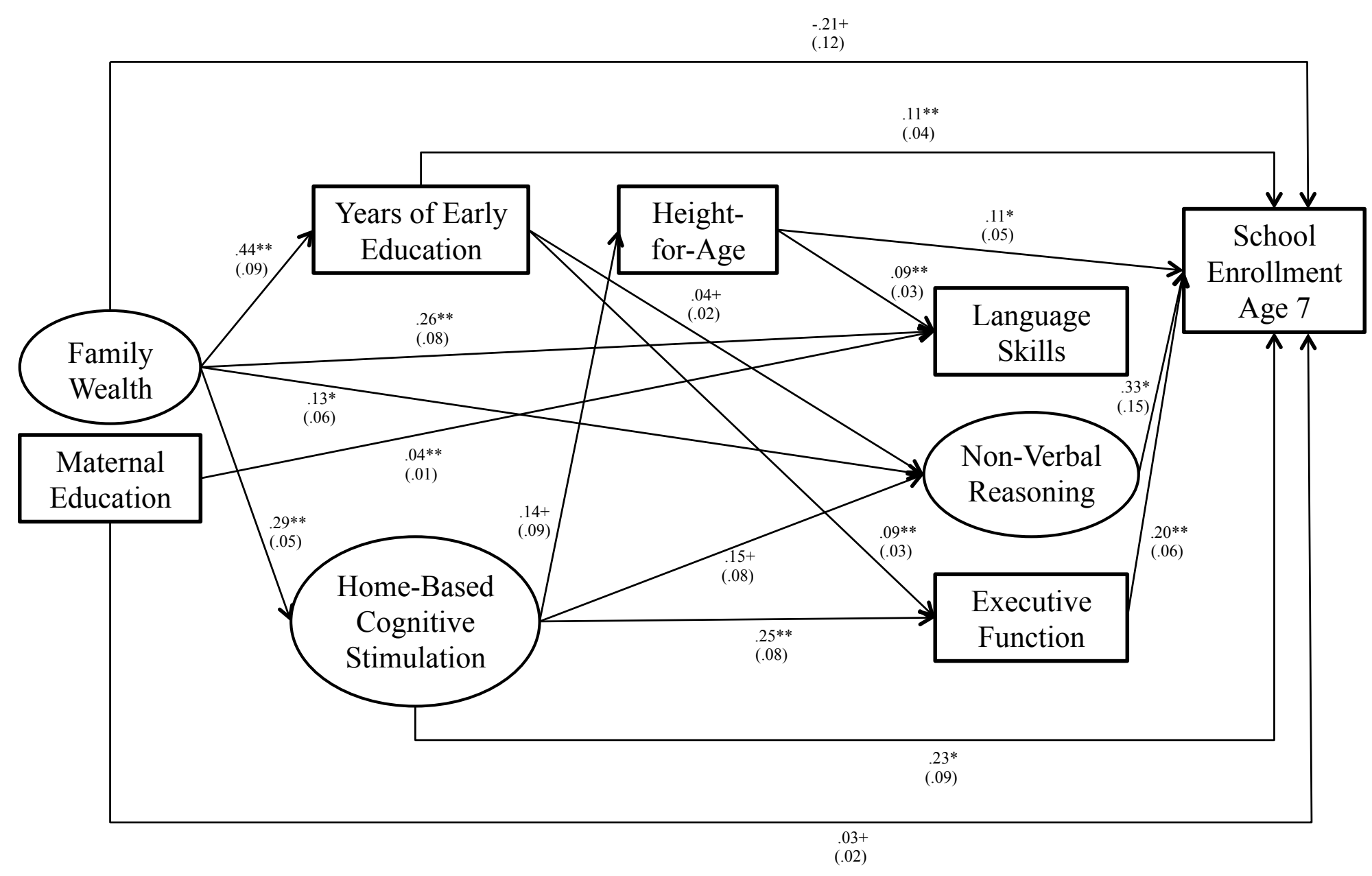

Figure 4. Final on-time (age 7) enrollment structural equation model results (Cohort 1 only; n=1766)

Notes: $+p<.10, * p<.05, * * p<.01$. Only significant, direct pathways shown. See Table 5 for coefficients and standard errors of significant indirect pathways. Covariates (child gender, child age, household size, region urbanicity, region wealth), residual correlations (between cognitive stimulation variables, and between cognitive skill variables), and embedded measurement models (for family wealth, home-based cognitive stimulation, and non-verbal reasoning) included in model but not shown. 
POVERTY, HEALTH, AND CHILD DEVELOPMENT

Table 1. Descriptive statistics

\begin{tabular}{|c|c|c|c|c|c|}
\hline & Valid N & $\begin{array}{c}\text { Mean or } \\
\%\end{array}$ & SD & Min & Мax \\
\hline Child gender (female) & 2711 & $48.40 \%$ & & & \\
\hline Cohort 1 & 1766 & $65.14 \%$ & & & \\
\hline Child age (in months) & 1766 & 74.47 & 4.05 & 67 & 84 \\
\hline \multicolumn{6}{|l|}{ Region } \\
\hline Central & 2711 & $2.95 \%$ & & & \\
\hline Copperbelt & 2711 & $22.17 \%$ & & & \\
\hline Eastern & 2711 & $10.92 \%$ & & & \\
\hline Luapula & 2711 & $15.64 \%$ & & & \\
\hline Lusaka & 2711 & $19.85 \%$ & & & \\
\hline Southern & 2711 & $14.53 \%$ & & & \\
\hline Western & 2711 & $13.94 \%$ & & & \\
\hline Urban region & 2711 & $49.80 \%$ & & & \\
\hline Average regional wealth score & 2631 & 3.25 & 1.13 & 1.25 & 5 \\
\hline Sum of family wealth items & 2711 & 3.05 & 2.32 & 1 & 7 \\
\hline Caregiver education (in years) & 2601 & 9.06 & 3.15 & 0 & 19 \\
\hline Sum of at-home cognitive stimulation items & 2711 & 1.41 & 1.09 & 0 & 3 \\
\hline Any children's books in home & 2711 & $29.44 \%$ & & & \\
\hline Any other books in home & 2711 & $63.89 \%$ & & & \\
\hline Adult reads to child & 2711 & $47.99 \%$ & & & \\
\hline Early childhood education (in years) & 2644 & 0.82 & 1.41 & 0 & 7 \\
\hline Child height-for-age & 2139 & -1.01 & 1.17 & -5.43 & 5.46 \\
\hline Child language (z-score) & 2711 & 0.00 & 1.00 & -4.10 & 1.63 \\
\hline $\begin{array}{l}\text { Average of non-verbal reasoning variables } \\
\text { (z-scores) }\end{array}$ & 2711 & 0.00 & 1.00 & -1.84 & 4.35 \\
\hline Child executive function (z-score) & 2695 & 0.00 & 1.00 & -1.11 & 2.35 \\
\hline Child enrolled in school early (age 6) & 2677 & $16.74 \%$ & & & \\
\hline $\begin{array}{l}\text { Child enrolled in school on time (age 7; } \\
\text { cohort } 1 \text { only) }\end{array}$ & 1206 & $31.34 \%$ & & & \\
\hline
\end{tabular}


POVERTY, HEALTH, AND CHILD DEVELOPMENT

Table 2. Bivariate correlations between latent and observed variables

\begin{tabular}{|c|c|c|c|c|c|c|c|c|c|c|c|c|c|c|c|}
\hline & & $(1)$ & $(2)$ & (3) & (4) & $(5)$ & $(6)$ & $(7)$ & $(8)$ & $(9)$ & $(10)$ & $(11)$ & $(12)$ & (13) & $(14)$ \\
\hline 1 & Child female & & & & & & & & & & & & & & \\
\hline 2 & Child age & -.017 & & & & & & & & & & & & & \\
\hline 3 & Household size & -.025 & $-.060 * *$ & & & & & & & & & & & & \\
\hline 4 & Urban region & .029 & $-.251 * *$ & $-.035+$ & & & & & & & & & & & \\
\hline 5 & Region wealth & $.051 * *$ & $-.227 * *$ & $-.060 * *$ & $.936 * *$ & & & & & & & & & & \\
\hline 6 & Household wealth & .018 & $-.157 * *$ & -.006 & $.640 * *$ & $.513 * *$ & & & & & & & & & \\
\hline 7 & Caregiver educ (yrs) & -.018 & $-.037 *$ & $.119 * *$ & $.302 * *$ & $.298 * *$ & $.567 * *$ & & & & & & & & \\
\hline 8 & Home-based cog stim & .020 & $-.058 * *$ & $.208 * *$ & $.160 * *$ & $.150 * *$ & $.441 * *$ & $.358 * *$ & & & & & & & \\
\hline 9 & Early child educ (yrs) & .020 & $-.122 * *$ & .006 & $.318 * *$ & $.308 * *$ & $.443 * *$ & $.280 * *$ & $.366 * *$ & & & & & & \\
\hline 10 & Height-for-age & $.040 *$ & .000 & $-.042 *$ & .027 & .001 & $.138 * *$ & $.122 * *$ & $.139 * *$ & $.138 * *$ & & & & & \\
\hline 11 & Language skills & .005 & $.107 * *$ & .029 & $.118 * *$ & $.133 * *$ & $.318 * *$ & $.289 * *$ & $.245 * *$ & $.153 * *$ & $.205^{* *}$ & & & & \\
\hline 12 & Non-verbal reasoning & $-.089 * *$ & $.088 * *$ & -.014 & .012 & $.042 *$ & $.286 * *$ & $.233 * *$ & $.330 * *$ & $.217 * *$ & $.189 * *$ & $.486^{* *}$ & & & \\
\hline 13 & Executive function & $-.051 * *$ & $.080 * *$ & $.034+$ & -.018 & $.053 * *$ & $.126 * *$ & $.122 * *$ & $.237 * *$ & $.161 * *$ & $.147 * *$ & $.250 * *$ & $.491 * *$ & & \\
\hline 14 & $\begin{array}{l}\text { Early school enrollment } \\
\text { (at age 6) }\end{array}$ & $.055^{* *}$ & $.094 * *$ & .007 & $.170 * *$ & $.182 * *$ & $.317 * *$ & $.255^{* *}$ & $.307 * *$ & $.326^{* *}$ & $.383 * *$ & $.232 * *$ & $.289 * *$ & $.267 * *$ & \\
\hline 15 & $\begin{array}{l}\text { On-time school } \\
\text { enrollment (at age 7) }\end{array}$ & $.040^{*}$ & $.065^{* *}$ & $.100 * *$ & $.298^{* *}$ & $.287 * *$ & $.248 * *$ & $.223 * *$ & $.316^{* *}$ & $.352 * *$ & $.147^{* *}$ & $.165^{* *}$ & $.331 * *$ & $.317 * *$ & $.392 * *$ \\
\hline
\end{tabular}

Note: $+p<.10, * p<.05, * * p<.01$ 
Table 3. Model fit statistics for early and on-time school enrollment models

\begin{tabular}{|c|c|c|c|c|c|}
\hline Model & $\chi^{2}$ & d.f. & RMSEA & CFI & WRMR \\
\hline 1) Primary early enrollment model (w/o covariates) & 189.852 & 122 & 0.014 & 0.991 & 0.76 \\
\hline \multicolumn{6}{|l|}{ 2) Alternative early enrollment models (w/o covariates) } \\
\hline A) Model w/o HAZ \& enrollment ("Western model”) & 593.541 & 137 & 0.035 & 0.941 & 1.968 \\
\hline B) Model w/o paths to early investment in learning & 901.007 & 126 & 0.048 & 0.901 & 2.599 \\
\hline C) Model w/o paths to early investment \& HAZ & 938.137 & 130 & 0.048 & 0.896 & 2.723 \\
\hline D) Model w/o paths to early investment, HAZ, \& cognitive skills & 1053.096 & 145 & 0.048 & 0.884 & 3.579 \\
\hline 3) Final early enrollment model (w/ covariates) & 518.629 & 202 & 0.024 & 0.940 & 1.366 \\
\hline 4) Final on-time enrollment model (Cohort 1 only; w/ covariates) & 446.645 & 203 & 0.026 & 0.942 & 1.267 \\
\hline
\end{tabular}

Note: $\mathrm{HAZ}=$ height-for-age $\mathrm{z}$ score 
POVERTY, HEALTH, AND CHILD DEVELOPMENT

Table 4. Loadings of observed variables on latent indicators in final early and on-time school enrollment models

\begin{tabular}{|c|c|c|c|c|c|c|}
\hline \multirow[b]{3}{*}{ Observed variable } & \multicolumn{3}{|c|}{ Early Enrollment Model } & \multicolumn{3}{|c|}{ On-Time Enrollment Model } \\
\hline & \multicolumn{2}{|c|}{$\begin{array}{c}\text { Unstandardized } \\
\text { coefficient }\end{array}$} & \multirow{2}{*}{$\begin{array}{c}\begin{array}{c}\text { Standardized } \\
\text { coefficient }\end{array} \\
B\end{array}$} & \multicolumn{2}{|c|}{$\begin{array}{c}\text { Unstandardized } \\
\text { coefficient }\end{array}$} & \multirow{2}{*}{$\begin{array}{c}\begin{array}{c}\text { Standardized } \\
\text { coefficient }\end{array} \\
B\end{array}$} \\
\hline & $b$ & SE & & $b$ & SE & \\
\hline \multicolumn{7}{|l|}{ Household wealth } \\
\hline Television & 1.00 & $(0.00)$ & 0.93 & 1.00 & $(0.00)$ & 0.94 \\
\hline Stove & 1.05 & $(0.02)$ & 0.98 & 1.04 & $(0.02)$ & 0.98 \\
\hline Electricity & 1.02 & $(0.01)$ & 0.95 & 1.03 & $(0.01)$ & 0.97 \\
\hline Water & 0.81 & $(0.05)$ & 0.75 & 0.82 & $(0.06)$ & 0.77 \\
\hline Radio & 0.65 & $(0.03)$ & 0.60 & 0.71 & $(0.04)$ & 0.67 \\
\hline Cell phone & 0.67 & $(0.04)$ & 0.62 & 0.65 & $(0.05)$ & 0.61 \\
\hline Solid floors & 0.78 & $(0.05)$ & 0.72 & 0.75 & $(0.06)$ & 0.70 \\
\hline \multicolumn{7}{|c|}{ Home-based cognitive stimulation } \\
\hline Children’s books & 1.00 & $(0.00)$ & 0.75 & 1.00 & $(0.00)$ & 0.73 \\
\hline Other books & 1.12 & $(0.08)$ & 0.84 & 1.10 & $(0.11)$ & 0.80 \\
\hline Adult reads to child & 0.98 & $(0.06)$ & 0.74 & 1.00 & $(0.09)$ & 0.73 \\
\hline \multicolumn{7}{|l|}{ Non-verbal reasoning } \\
\hline NEPSY & 1.00 & $(0.00)$ & 0.61 & 1.00 & $(0.00)$ & 0.57 \\
\hline Kaufman Pattern Reasoning & 0.98 & $(0.09)$ & 0.59 & 1.11 & $(0.16)$ & 0.60 \\
\hline Tactile Patterns & 1.13 & $(0.13)$ & 0.68 & 1.22 & $(0.20)$ & 0.70 \\
\hline
\end{tabular}


Table 5. Results of final early and on-time enrollment model indirect pathways (statistically significant paths only)

\begin{tabular}{|c|c|c|c|c|}
\hline \multirow[t]{2}{*}{ Pathway } & \multicolumn{2}{|c|}{$\begin{array}{l}\text { Early } \\
\text { Enrollment Model } \\
\text { Indirect effect } a \times b\end{array}$} & \multicolumn{2}{|c|}{$\begin{array}{l}\text { On-Time } \\
\text { Enrollment Model } \\
\text { Indirect effect } a x b\end{array}$} \\
\hline & Coeff & (S.E.) & Coeff & (S.E.) \\
\hline \multicolumn{5}{|l|}{$H A Z$} \\
\hline Wealth $\rightarrow$ Early child educ $\rightarrow$ HAZ & $0.034 * *$ & $(0.012)$ & & \\
\hline Wealth $\rightarrow$ Home-based cog stim $\rightarrow$ HAZ & $0.036^{*}$ & $(0.016)$ & & \\
\hline Caregiver educ $\rightarrow$ Home-based cog stim $\rightarrow$ HAZ & $0.004+$ & $(0.002)$ & & \\
\hline \multicolumn{5}{|l|}{ Language } \\
\hline Wealth $\rightarrow$ Home-based cog stim $\rightarrow$ Language & $0.037 *$ & $(0.018)$ & & \\
\hline Wealth $\rightarrow$ Early child educ $\rightarrow$ HAZ $\rightarrow$ Language & $0.004 * *$ & $(0.001)$ & & \\
\hline Wealth $\rightarrow$ Home-based cog stim $\rightarrow$ HAZ $\rightarrow$ Language & $0.004 *$ & $(0.002)$ & & \\
\hline Caregiver educ $\rightarrow$ Home-based $\operatorname{cog}$ stim $\rightarrow$ HAZ $\rightarrow$ Language & $0.000+$ & $(0.000)$ & & \\
\hline \multicolumn{5}{|l|}{ Non-verbal reasoning } \\
\hline Wealth $\rightarrow$ Home-based cog stim $\rightarrow$ Non-verbal reasoning & $0.052 * *$ & $(0.019)$ & $0.043+$ & $(0.024)$ \\
\hline Caregiver educ $\rightarrow$ Home-based cog stim $\rightarrow$ Non-verbal reasoning & $0.005+$ & $(0.003)$ & & \\
\hline Wealth $\rightarrow$ Early child educ $\rightarrow$ HAZ $\rightarrow$ Non-verbal reasoning & $0.002 *$ & $(0.001)$ & & \\
\hline \multicolumn{5}{|l|}{ Executive function } \\
\hline Wealth $\rightarrow$ Early child educ $\rightarrow$ Exec function & $0.020 *$ & $(0.009)$ & $0.041 * *$ & $(0.015)$ \\
\hline Wealth $\rightarrow$ Home-based cog stim $\rightarrow$ Exec function & $0.075 * *$ & $(0.020)$ & $0.071 * *$ & $(0.023)$ \\
\hline Caregiver educ $\rightarrow$ Home-based cog stim $\rightarrow$ Exec function & $0.007 *$ & $(0.003)$ & & \\
\hline Wealth $\rightarrow$ Early child educ $\rightarrow$ HAZ $\rightarrow$ Exec function & $0.003 *$ & $(0.002)$ & & \\
\hline Wealth $\rightarrow$ Home-based cog stim $\rightarrow$ HAZ $\rightarrow$ Exec function & $0.003+$ & $(0.002)$ & & \\
\hline Caregiver educ $\rightarrow$ Home-based $\operatorname{cog}$ stim $\rightarrow$ HAZ $\rightarrow$ Exec function & $0.000+$ & $(0.000)$ & & \\
\hline \multicolumn{5}{|l|}{ School enrollment } \\
\hline Wealth $\rightarrow$ Early child educ $\rightarrow$ School enroll & $0.061 * *$ & $(0.016)$ & $0.043+$ & $(0.026)$ \\
\hline Wealth $\rightarrow$ Home-based cog stim $\rightarrow$ School enroll & & & $0.065^{*}$ & $(0.030)$ \\
\hline Wealth $\rightarrow$ Non-verbal reasoning $\rightarrow$ School enroll & & & $0.043+$ & $(0.026)$ \\
\hline Early child educ $\rightarrow$ HAZ $\rightarrow$ School enroll & $0.019 * *$ & $(0.006)$ & & \\
\hline Early child educ $\rightarrow$ Exec function $\rightarrow$ School enroll & $0.005+$ & $(0.003)$ & $0.018^{*}$ & $(0.009)$ \\
\hline Home-based cog stim $\rightarrow$ HAZ $\rightarrow$ School enroll & $0.031 *$ & $(0.014)$ & & \\
\hline Home-based cog stim $\rightarrow$ Exec function $\rightarrow$ School enroll & $0.032 *$ & $(0.015)$ & & \\
\hline Wealth $\rightarrow$ Early child educ $\rightarrow$ HAZ $\rightarrow$ School enroll & $0.009 *$ & $(0.003)$ & & \\
\hline Wealth $\rightarrow$ Home-based cog stim $\rightarrow$ HAZ $\rightarrow$ School enroll & $0.009 *$ & $(0.004)$ & $0.049 *$ & $(0.022)$ \\
\hline
\end{tabular}




\begin{tabular}{lllll}
\hline Wealth $\rightarrow$ Early child educ $\rightarrow$ Exec function $\rightarrow$ School enroll & $0.003+$ & $(0.001)$ & $0.008+$ & $(0.004)$ \\
Wealth $\rightarrow$ Home-based cog stim $\rightarrow$ Exec function $\rightarrow$ School enroll & $0.009^{*}$ & $(0.005)$ & & \\
Caregiver educ $\rightarrow$ Home-based cog stim $\rightarrow$ HAZ $\rightarrow$ School enroll & $0.001+$ & $(0.000)$ & & \\
Caregiver educ $\rightarrow$ Home-based cog stim $\rightarrow$ Exec function $\rightarrow$ School enroll & $0.001+$ & $(0.001)$ & $0.014^{*}$ & $(0.007)$ \\
\hline
\end{tabular}

Notes: $+p<.10, * p<.05, * * p<.01$; Wealth $=$ household wealth latent variable; Caregiver educ $=$ caregiver years of education; Early child educ $=$ child years of early childhood education; Home-based cog stim $=$ home-based cognitive stimulation latent variable; HAZ $=$ height-for-age $\mathrm{z}$-score; Language = child language skills; Non-verbal reasoning = child non-verbal reasoning latent variable; Exec function = child executive functioning; School enroll = child's enrollment in primary school at age 6 (for early model) or age 7 (for on-time model) 